LWSA

PAPER - OPEN ACCESS

\title{
The Response of Chinese Language Students Readers to Huo Zhe (活着 ) Novel by Yu Hua: Literary Reception Study
}

\author{
Author $\quad:$ Intan Erwani and Julina \\ DOI $\quad: 10.32734 /$ lwsa.v3i4.1135 \\ Electronic ISSN $\quad: 2654-7066$ \\ Print ISSN : 2654-7058
}

Volume 3 Issue 4-2020 TALENTA Conference Series: Local Wisdom, Social, and Arts (LWSA)

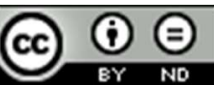

This work is licensed under a Creative Commons Attribution-NoDerivatives 4.0 International License.

Published under licence by TALENTA Publisher, Universitas Sumatera Utara

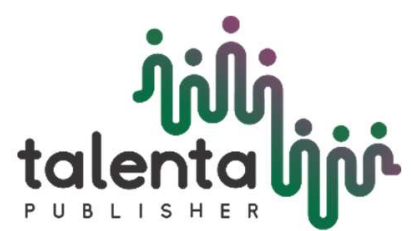




\title{
jibli talentaliois \\ LWSA Conference Series 03 (2020) \\ The Response of Chinese Language Students Readers to Huo Zhe (活着) Novel by Yu Hua: Literary Reception Study
}

\author{
Intan Erwani ${ }^{\mathrm{a}}$, Julina ${ }^{\mathrm{b} *}$ \\ ${ }^{a}$ Chinese Language Study Program, Faculty of Cultural Sciences, University of Sumatera Utara, Jalan Dr. T. Mansur No. 9 Medan, 20222, Indonesia \\ ${ }^{b}$ Chinese Language Study Program, Faculty of Cultural Sciences, University of Sumatera Utara, Jalan Dr. T. Mansur No. 9 Medan, 20222, Indonesia \\ intanerwany@gmail.com,julina@usu.ac.id
}

\begin{abstract}
This study discussed the responses of readers from Chinese language students at the University of Sumatera Utara towards Yu Hua's novel Huo Zhe (活着). This study aimed to determine the responses given by students to Huo Zhe (活着) novel by Yu Hua. The theory used was literary reception theory which focused on exploring various judgments, responses and impressions hence a literary work can be accepted by its presence in society. The methodology used was a qualitative descriptive method. The research informants were 35 students majoring in the Chinese Language in semesters 6th and 8th who had taken a concentration in literature. Informants will be asked to read Yu Hua's novel Huo Zhe (活着 ) and provide their responses through questionnaires. The results of this study indicated that the Huo Zhe (活着) novel fulfilled all the evaluation criteria for novelty, impact and design as proposed by Segers. Thus, from the three evaluations, it can be concluded that the reading informants from the 6th and 8th semester students of Chinese Language accept the presence of the Huo Zhe (活着) novel as good and positive reading material.
\end{abstract}

Keywords: Literary Reception; Responses; Segers; Huo Zhe; Yu Hua.

\section{Introduction}

Along with the times, literature has an important role in strengthening knowledge of a language and even the origin of a nation. Literature as a work of human art offers various images of life, such as customs, culture, history and politics, which can stimulate readers responding to something. Kurniawan (2012: 2) stated that literature is a cultural system as a representation of human thoughts that represent their collectivity in social life. Based on this opinion, it can be said that literature has a unique relationship with the socio-cultural system as the basis of life; hence literature will always live and be lived by the community. The existence of literature is also strengthened by readers who enjoy and take advantage of literary works to interpret every phenomenon that occurs in life. Without the reader, the literary function has no role to play. In other words, the relationship between literature and readers is like a link that can move and respond to its developments.

Readers have an important position in the world of literature, especially Chinese literature. Chinese literature is one of the oldest works of literature in the world which has a long journey in describing Chinese civilization. Ancient to contemporary literary works are also read and studied by students of the Chinese Language study program, Faculty of Cultural Sciences, University of Sumatera Utara. Students are introduced to literary works originating from China through the literature courses offered by the Chinese Language study program. In line with that, literary works depicting Chinese culture are also read, studied and interpreted by students. However, in interpreting literary works, many students experienced several problems in understanding the meaning or message of the story. One of the obstacles from the observation results appears to be the differences in the cultural background and ethnic diversity of each student which causes the meaningful process of literary works whose context is Chinese culture less well understood. Moreover, the understanding of student culture as formed by the local environment results in differences in responses and assessments.

The responses made by readers to literary works are part of the realm of literary reception studies. According to Sehandi (2014: 157), literary receptions can be defined as text processing; ways of giving meaning by readers to literary works, hence they can respond to them. Therefore, this study focused on discussing the problems about the response of Chinese Language Study Program student, Faculty of Cultural Sciences, University of Sumatera Utara to Yu Hua's novel Huo Zhe (活着). The novel, written in 1998 by Yu Hua, had received an award from Grinzane Cavour Price in 1998 and an Order of Arts and Letter from the French Ministry of Culture in 2004. This novel was chosen as reading material for readers because it tells in detail about the twists and turns of 
Chinese people's experiences in facing and surviving the major events experienced by the Chinese nation, namely the Cultural Revolution. In addition, the characters that have a variety of characters and complex storylines are very interesting for readers to comment on and respond to.

Readers who provide their responses and comments as research informants are 35 students in semester 6 and 8 , with a concentration in literature. These informants were selected on the basis that the 6th and 8th semester students were active readers who had received introductory literature courses, had read Chinese literature and had studied prose. Thus, this study focused on discussing the problem of readers' responses from 6th and 8th semester students of the Chinese Language Study Program, Faculty of Cultural Sciences, University of Sumatera Utara to Yu Hua's novel Huo Zhe (活着).

\section{Literary Reception Theory}

Pragmatically, literature has a use-value that can be utilized by every human being. This view underlies an approach called literary reception. Literary reception comes from the Latin word recipere which means receiving or enjoying literary works by the reader. Segers (2000: 35) defines literary reception as a teaching that investigates literary texts on the basis of real and possible reader reactions to a literary text. This science is often called rezeptionaesthetic which is translated as (a) Literary response, (b) Aesthetic reception, or (c) Literary reception. In Indonesia, this knowledge is translated and is better known as the literary reception theory.

Literary reception focuses its attention on the process of linking text and readers, which is mostly directed at the interpretive phase of the reading process. In Endaswara's (2008: 118) viewed that this process is closely related to evaluation when the reader gives a value judgment to a particular text. A value judgment is a proposition that is able to rationalize the evaluative reaction of the reader to a particular text and which is rated by the reader. Based on this definition, a value judgment is based on two elements, namely the reader norm system and the text structure. Correspondingly, Segers offers a model diagram to see the evaluation process of value judgment.

$$
\text { Reader + literary norm system }
$$

Fig 1. Value Judgments

In this diagram, the "reader" element appears as something that symbolizes that the value judgment is influenced by special situations. The special situation formed by the norm system can be used by the reader to determine the quality of the text. Therefore, through this value judgment, readers who have finished reading literary works can provide judgments and impressions. Furthermore, the evaluation system with this value judgment is divided by Segers (2000: 158) into three categories/evaluation factors, namely novelty factors, impact factors, and design factors. The first factor consists of the criteria for language, originality, joy, and interest. The second factor includes the criteria for emotion, reasonableness, characterization, involvement, and tempo. The third factor includes the plot, theme, and structure.

With the value judgment at literary receptions, readers are given space to respond to literary works. Literary works that are dynamic in nature and move from time to time always get responses from their readers. In line with that, in literary receptions, the text of literary works is also seen as something concrete through an acceptance of the reader so as to leave an impression (wirkung) on the reader. However, this impression cannot exist without the reader's imagination, because without the reader's imagination it is impossible to see literary works in a broader relationship. This is also explained by Junus (1985: 51) that the reader's imagination is made possible by familiarity with the literary tradition and the ability to understand conditions in his time and possibly in the past.

Thus, literary receptions can lead readers to be able to express acceptance or not of a literary work through a series of assessments, responses and impressions. The reader can state it in the form of a commentary or perhaps in another work which relates to the previous work in some way.

\section{Research methods}

In this research, the method used was the descriptive qualitative method. Nazir in Prastowo (2011: 186) defined that a qualitative descriptive method is a method used to examine the status of a group of people, an object, and a set of conditions, a system of thought, or a class of events in the present. Qualitative descriptive research is intended to describe and portray existing phenomena, both natural and human engineering, which pay more attention to the characteristics, quality, and linkages between activities (Sukmadinata, 2011: 73). Descriptive research also emphasizes the description of an existing condition which is carried out through observation and continued by distributing questionnaires. In line with that, to facilitate the exposure of qualitative descriptive research results, numerical tabulations in table form are also used to present the data. 
In addition, the literary reception method in this study was carried out synchronously, that is, examining literary receptions in one period of time. The synchronous method was chosen because the research informants as readers are currently active in the Chinese Language Study Program, Faculty of Cultural Sciences, University of Sumatera Utara.

\section{Discussion}

This chapter presented an analysis of reader responses, namely students in semester 6 and 8 of the Chinese Language study program, Faculty of Cultural Sciences, University of Sumatera Utara. This study involved 15 informants at the semester 6 level and 20 people at the semester 8 levels. The total number of informants was 35 people with 4 men and 31 women. This discussion was also based on the theory of Segers which specifically discussed literary reception. For the presentation of the research results, the data was displayed using tabulated numbers in the form of tables to make it easier to present the data in detail. Once described in tabular form, then the data were described using qualitative descriptive methods. This analysis was also divided into 3 response criteria according to Segers' theory of literary reception, namely responses based on novelty, impact and design.

\subsection{Reader's Response Based on Novelty Criteria to Yu Hua's Huo Zhe (活着) Novel}

This section discussed the responses given by informants related to novelty criteria or updates to novels. The responses focused on the language, originality, excitement and interest of the informants towards the novel. In this case, language is a medium for conveying the creative ideas used by the author to the reader. This criterion was deliberately chosen considering that the use of language is one aspect that needs to be considered, besides that language can also lead someone to interpretations during the reading process of a literary work. Huo Zhe (活着) novel is one of the literary works from China that used Mandarin. This is increasingly appropriate and relevant because all informants involved are students of the Chinese language study program, hence it is considered appropriate for them to provide an assessment of this aspect. Therefore, the language assessment questionnaire focused on easy language understanding, skillful and structured language presentation of the Huo Zhe (活着) novel. This can be seen in the data table as follows:

Table 1. Questionnaire Data for Language Assessment.

\begin{tabular}{lccccc}
\hline Scoring scale & 1 & 2 & 3 & 4 & Total \\
\hline Number of respondents (people) & 0 & 1 & 25 & 9 & 35 \\
Percentage $(\%)$ & 0 & 2,9 & 71,4 & 25,7 & 100 \\
\hline
\end{tabular}

Based on Table 1, all informants provide the language assessment to the novel. The total number of informants who gave the assessment was 35 people. The informants did not give 1 as a score. The lowest score given by the informants was 2 and the highest score was 4 . When we look at the data, only 1 person with a percentage of $2.9 \%$ chose the answer to disagree with the easy language presentation in the novel. Then, as many as 25 people, who mean $71.4 \%$, thought that the novel has the convenience and good language structure. Furthermore, of the total information, there were 9 people or $25.7 \%$ gave a value of 4 which stated that this novel has excellent ease of understanding language.

Based on the data that has been obtained, and then the data was processed again to find the average assessment of the informant readers of the novel. This can be seen in the table as follows:

Table 2. Average Value of Readers' Responses for Language Elements.

\begin{tabular}{lccccc}
\hline & N & Minimum & Maximum & Mean & $\begin{array}{c}\text { Std. } \\
\text { Deviation }\end{array}$ \\
\hline N Valid general criteria & 35 & 2 & 4 & 3,23 & 0,49 \\
\hline
\end{tabular}

Based on this table, it showed that the minimum score given by the informants was 2 and the maximum score was 4 . The average score obtained was 3.23. Based on this average score, it can be interpreted that the Huo Zhe (活着) novel was well responded to in terms of the presentation of Chinese language which is easily understood by students of the Chinese Language Department.

Furthermore, the novelty criterion also consists of elements of originality. This element measures the extent to which the reader responds that the Huo Zhe (活着) novel can show authenticity or originality, providing a different and refreshing idea or perspective. Therefore, the originality assessment questionnaire was focused on the relation of original and different perceptions and ideas. This can be seen in the table as follows: 
Table 3. Questionnaire Data for Assessment of Originality.

\begin{tabular}{lccccc}
\hline Scoring scale & 1 & 2 & 3 & 4 & Total \\
\hline Number of respondents (people) & 0 & 0 & 23 & 12 & 35 \\
Percentage $(\%)$ & 0 & 0 & 65,7 & 34,3 & 100 \\
\hline
\end{tabular}

Based on table 3, all informants gave an assessment of the Huo Zhe (活着) novel. The total number of informants who gave an assessment was 35 people. Informants did not provide ratings on scores 1 and 2 . The lowest score given by the informants on the originality of the novel was 3 and the highest score was 4.23 informants gave a score of 3 with a percentage of $65.7 \%$, which means that the elements of originality are well described in the novel. A total of 12 people gave a score of 4 with a percentage of $34.3 \%$, which means that this novel displays different ideas and perspectives very well.

Based on the results of data analysis, hence the data were reprocessed to obtain the average assessment of the informants. This can be seen in the table as follows:

Table 4. Average Reader's Response Score for the Element of Originality.

\begin{tabular}{lccccc}
\hline & N & Minimum & Maximum & Mean & $\begin{array}{c}\text { Std. } \\
\text { Deviation }\end{array}$ \\
\hline N Valid general criteria & 35 & 3 & 4 & 3,34 & 0,48 \\
\hline
\end{tabular}

Based on Table 4, it showed that the minimum score given was 3, while the maximum score was 4. The average score obtained was 3.34. Based on these scores, it can be interpreted that the Huo Zhe (活着) novel was well responded in showing the authenticity of story ideas hence it can provide a different and new perspective for the Chinese Language Department students.

In addition, the novelty criterion also consists of an element of the reader's joy. This element is useful for knowing the extent to which the main issues and problems in the novel can give joy to the reader or not. However, this aspect is a subjective assessment because this assessment is related to the harmony of the hearts of each reader. Through a questionnaire submitted to readers, the assessment given to reader satisfaction can be seen in the table below:

Table 5. Questionnaire Data for Joy Assessment.

\begin{tabular}{lccccc}
\hline Scoring scale & 1 & 2 & 3 & 4 & Total \\
\hline Number of respondents (people) & 0 & 13 & 19 & 3 & 35 \\
Percentage $(\%)$ & 0 & 37,1 & 54,3 & 8,6 & 100 \\
\hline
\end{tabular}

Based on Table 5, all informants gave an assessment of the Huo Zhe (活着) novel. The total number of informants who gave an assessment was 35 people. Informants did not give an assessment of score 1 . In this section, the lowest score given by the informant was at score 2 and the highest score was at score 4 . The informants who gave score 2 were 13 people (37.1\%), which mean that the informants did not feel the impact of joy on the novel. Then, the informants who gave an assessment on score 3 were 19 people $(54.3 \%)$, who mean that the story presented by the novel gives a happy impression to the reader. Score 4 was given by 3 people $(8.6 \%)$, who strongly agreed that this novel gave the reader a happy and satisfying impression. The results of the data analysis were then reprocessed to obtain the average score. The following were the results of the data processing:

\begin{tabular}{lccccc}
\multicolumn{7}{l}{ Table 6. Average Reader's Responses to the Joyful Element } \\
\hline N & Minimum & Maximum & Mean & $\begin{array}{c}\text { Std. } \\
\text { Deviation }\end{array}$ \\
\hline N Valid general criteria & 35 & 2 & 4 & 2,71 & 0,62
\end{tabular}

Based on Table 6, it can be seen that the minimum score given by the informant was 2 , while the highest score was 4 . The average value obtained through the results of the assessment data processing was 2.71. Based on these average scores, it can be interpreted that the Huo Zhe (活着) novel did not give the reader the impression of joy and satisfaction.

Furthermore, the last part of the novelty criterion is the element of interest. With the assessment of readers' interest, it is expected to be able to measure intellectual challenges that lead readers to carry out further analysis. This was based on the fact that literary works have broad dimensions and require a lot of further analysis to uncover the natural puzzles represented by the work. Therefore, the interest assessment questionnaire focused on encouragement to conduct analytical studies. This can be seen in the table as follows: 
Table 7. Questionnaire Data for Interest Assessment.

\begin{tabular}{lccccc}
\hline Scoring scale & 1 & 2 & 3 & 4 & Total \\
\hline Number of respondents (people) & 0 & 3 & 27 & 5 & 35 \\
Percentage $(\%)$ & 0 & 8,6 & 77,1 & 14,3 & 100 \\
\hline
\end{tabular}

Based on Table 7, all informants gave an assessment of the Huo Zhe (活着) novel. The total number of informants who gave an assessment was 35 people. The informant did not give an assessment on a score of 1 . The lowest score given by the informants was 2 and the highest was 4 . There were 3 informants who give a score of 2 with a percentage of $8.6 \%$, which means they did not agree that this novel can attract their interest to do an analytical study. Then, 27 people with a percentage of $77.1 \%$ chose a score of 3 , which means that they agree if the novel was of interest from an analysis point of view. Meanwhile, 5 people with a percentage of $14.3 \%$ prefer to give a score of 4 which means that they strongly agree that this novel can increase their interest to be used as study material related to the problem issues presented by the novel.

Based on the data from the informants' assessment, then it was reprocessed to obtain the average score which can be seen as follows:

Table 8. Average Value of Readers' Responses for Element of Interest

\begin{tabular}{lccccc}
\hline & N & Minimum & Maximum & Mean & $\begin{array}{c}\text { Std. } \\
\text { Deviation }\end{array}$ \\
\hline N Valid general criteria & 35 & 2 & 4 & 3,06 & 0,48 \\
\hline
\end{tabular}

Based on Table 8, it showed the lowest score was 2 and the highest was 4 . The average score obtained was 3.06. Based on these scores, it can be interpreted that the Huo Zhe (活着) novel was well responded to in terms of interest for further analysis by Chinese language students. Referring to Segers' view which explained the value judgment, in this context the reader can give a value judgment on the text they read. Thus, the results of the value judgments related to the aspect of interest were responded well, hence the Huo Zhe (活着) novel was worthy of being used as further analysis.

\subsection{Reader's Response Based on the Impact Factors on Yu Hua's Novel Huo Zhe (活着)}

This section discussed the responses given by the informants regarding the impact criteria of the novel. These responses focused on the emotional side, reasonable, characterization, engagement and tempo. Emotion is a condition that describes the feelings that a person feels. Therefore, when someone reads a literary work consciously or unconsciously he/she is led to enter the story by the author. Through the text of diction and sentences arranged in the story, it is able to bring the reader to imagine and animate the characters being told. This has an indirect impact on the reader's emotions. Thus, the emotional aspect was chosen to measure the extent of the psychological influence of the novel on the reader. The results of the responses given by informants through questionnaires based on emotional aspects of the Huo Zhe (活着) novel were as follows:

Table 9. Questionnaire Data for Emotion Assessment.

\begin{tabular}{lccccc}
\hline Scoring scale & 1 & 2 & 3 & 4 & Total \\
\hline Number of respondents (people) & 0 & 1 & 17 & 17 & 35 \\
Percentage $(\%)$ & 0 & 2,9 & 48,6 & 48,6 & 100 \\
\hline
\end{tabular}

Based on Table 9, all informants provide an assessment of the Huo Zhe (活着) novel. The total number of informants who gave an assessment was 35 people. The informant did not give 1 as a score. The lowest score related to the reader's emotions in the Huo Zhe (活着) novel was 2 and the highest score was 4 . The informant who gave a score of 2 was only 1 person with a percentage of $2.9 \%$, which means that he/she did not feel the emotional impact or did not affect her/his psychology. Furthermore, the informants who gave a score of 3 were 17 people with a percentage of $48.6 \%$, which means that the readers agreed that this novel also influenced their emotions. Based on Table 9, the informants who gave a score of 3 and a score of 4 are the same. The informants who gave a score of 4 were 17 people with a percentage of $48.6 \%$. This means that readers thought that this novel has a great influence on emotions hence they can animate and feel the character's attitudes and characters. Based on the data from the informants' assessment, then it is reprocessed to obtain the average score which can be seen as follows:

Table 10. Average Reader's Response Score for Emotional Elements

\begin{tabular}{llllc}
\hline N & Minimum Maximum Mean & $\begin{array}{c}\text { Std. } \\
\text { Deviation }\end{array}$ \\
\hline
\end{tabular}


Based on Table 10, it showed that the minimum score given by the informants was 2 and the maximum score was 4 . The average score obtained was 3.46. Based on this average score, it can be interpreted that the Huo Zhe (活着) novel was able to inflict an emotional impact hence it is responded well by students majoring in the Chinese language. This was in line with Segers' viewed of value judgment which places the relationship between text and reader. The text that is covered with various ideas about emotions and feelings can be responded to by the reader through a value judgment. Thus, the results of the value judgments related to the emotional aspects of the novel showed a good direct and indirect impact and also influence on the reader.

Furthermore, the impact criterion also consists of reasonable or logical elements. This element is used as part of the assessment with the aim of knowing the level of the story logical value contained in the novel, because in conflict and story resolution there is a coherent and logical link. People can state one matter to be logical, if it can be accepted according to reason and consideration. In this assessment, there were data on the results of the scores given by the informants in their assessment regarding the reasonable side of the Huo Zhe (活着) novel:

Table 11. Questionnaire Data for Reasonable Assessments.

\begin{tabular}{lccccc}
\hline Scoring scale & 1 & 2 & 3 & 4 & Total \\
\hline Number of respondents (people) & 0 & 1 & 24 & 10 & 35 \\
Percentage $(\%)$ & 0 & 2,9 & 68,6 & 28,6 & 100 \\
\hline
\end{tabular}

Based on Table 11, all informants provide an assessment of the Huo Zhe (活着) novel. The total number of informants who gave an assessment was 35 people. The informant did not give an assessment of score 1 . From the data above, it appears that the informant gave the lowest score at 2 and the highest at 4 . The informant who gave a score of 2 was only 1 person with a percentage of $2.9 \%$, which means that the novel was not logically accepted by the informant. There were 24 informants who gave a score of 3 with a percentage of $68.6 \%$, which means that the novel was logically accepted by the informant. The last assessment on a score of 4 , which was as many as 10 people with a percentage of $28.6 \%$, which means that the novel was very well accepted by the informant rationally. The results of the data analysis were then reprocessed to obtain the average score. The following were the results of the data processing:

Table 12. Average Reader's Response Score for Reasonable Elements

\begin{tabular}{lccccc}
\hline & N & Minimum & Maximum & Mean & $\begin{array}{c}\text { Std. } \\
\text { Deviation }\end{array}$ \\
\hline N Valid general criteria & 35 & 2 & 4 & 3,26 & 0,50 \\
\hline
\end{tabular}

Based on Table 12. it showed that the minimum score given by the informants was 2 and the maximum score was 4 . The average score obtained was 3.26. Based on this average score, it can be interpreted that the novel's story was well received by the reader's logic.

Next, the impact criteria consist of characterization elements. This element is recognized by other terms, namely character and characterization. In this case, the totality of the work is reflected when the characters and characterization in the story work together. In addition, the problem of character and characterization is crucial and decisive in a literary work, because the character who acts as this play will later form a plot. Even more than that, the depiction of a character must appear in a strong connection to form his/her individual impression and personality. Therefore, the questionnaire focused on the visualization of characters possessed by characters in the novel. This can be seen in the table as follows:

Table 13. Questionnaire Data for Characterization Assessment.

\begin{tabular}{lccccc}
\hline Scoring scale & 1 & 2 & 3 & 4 & Total \\
\hline Number of respondents (people) & 0 & 0 & 23 & 12 & 35 \\
Percentage $(\%)$ & 0 & 0 & 65,7 & 34,3 & 100 \\
\hline
\end{tabular}

Based on Table 13, all informants provide an assessment of the Huo Zhe (活着) novel. The total number of informants who gave an assessment was 35 people. Informants did not provide ratings on scores 1 and 2 . Through this assessment table, it showed that the informant gave the lowest score at 3; while the highest score given was 4 . The informants who gave a score of 3 were 23 people with a percentage of $65.7 \%$, which means that the informant agreed that the character or personality of the character can be visualized in real life people's personalities. Then, the informants who gave a value of 4 were 12 people with a percentage of 
$34.3 \%$, which means that the informants strongly agreed that the characterization of the characters can be visualized in real-life human or community personalities. The results of the data analysis were then reprocessed to obtain the average score. The following were the results of the data processing:

Table 14. Average Score of Readers' Responses for Characterization Elements

\begin{tabular}{lccccc}
\hline & N & Minimum & Maximum & Mean & $\begin{array}{c}\text { Std. } \\
\text { Deviation }\end{array}$ \\
\hline N Valid general criteria & 35 & 3 & 4 & 3,34 & 0,48 \\
\hline
\end{tabular}

Based on Table 14, it showed that the minimum score given by the informants was 3 and the maximum score was 4 . The average score obtained was 3.34. Based on these scores, it can be interpreted that the reader can recognize and imagine each personality that was played by the characters in the novel well. If we refer to Segers' view of the value judgment that places the relationship between the text and the reader, then the character was positioned as text. The text, which displays various variations in character and characterization, was then responded to by the reader through the value judgments. Thus, the results of the value judgments related to the characterization aspect showed the impact felt by the reader in visualizing or imagining the character of the characters by relating the personalities possessed by the community.

Furthermore, another impact criterion is the element of involvement. This element is useful for measuring the reader's involvement in literature. This is based on the fact that a reader who is struggling with a literary work establishes contact between himself and the work being read. This assessment is considered relevant to be used as a parameter of how much individual involvement in the reading process of the novel, both in terms of character and characterization. It also distinguishes involvement of engagement and emotions. Specifically, the involvement assessment measures the reader's involvement with the work during the reading process, while the emotional aspect measures the effect or impact on feelings after the reading process. Therefore, the questionnaire focused on the connection between the reader's thoughts and the exposure of the novel. This can be seen in the table as follows:

Table 15. Questionnaire Data for Involvement Assessment.

\begin{tabular}{lccccc}
\hline Scoring scale & 1 & 2 & 3 & 4 & Total \\
\hline Number of respondents (people) & 0 & 2 & 26 & 7 & 35 \\
Percentage $(\%)$ & 0 & 5,7 & 74,3 & 20 & 100 \\
\hline
\end{tabular}

Based on Table 15, all informants provide an assessment of the Huo Zhe (活着) novel. The total number of informants who gave an assessment was 35 people. The informant did not give an assessment on a score of 1 . The lowest score given was 2 and the highest score was 4 . The informants who gave a score of 2 were 2 people with a percentage of $5.7 \%$, which means they did not feel any contact involving the mind with the novel. Furthermore, the informants who gave a score of 3 were 26 people with a percentage of $74.3 \%$, which means that they agreed that the novel plays a role in bringing a relationship of involvement with the reader's mind. Meanwhile, the informants who gave a score of 4 were 7 people with a percentage of $20 \%$, which means that the informants had a very close contact relationship during the reading process of the novel. The results of the data that have been obtained were then reprocessed to obtain the average score. The following were the results of the data processing:

Table 16. Average Reader's Response Score for Involvement Elements

\begin{tabular}{lcccccc}
\hline & N & Minimum & Maximum & Mean & $\begin{array}{c}\text { Std. } \\
\text { Deviation }\end{array}$ \\
\hline N Valid general criteria & 35 & 2 & 4 & 3,14 & 0,49 \\
\hline
\end{tabular}

Table 16. showed the minimum score given by the informants was 2 and the maximum score was 4 . The average score obtained by 35 informants was 3.14. Based on these scores, it can be interpreted that the narrative presented by the novel can bring the reader to the involvement of thoughts and feelings through the characters or characterization. Therefore, if we refer to Segers' view of the value judgment which places the relationship between the text and the reader, then the suggestion of involvement is in the text. The text will display the power of suggestion that involves the thoughts and feelings of the reader hence the readers can respond to this power in the form of the value judgments. Thus, the results of the value judgments related to the aspect of involvement showed the impact felt by the reader in a relationship framework that involves thoughts and feelings towards the novel.

Furthermore, the last part of the impact criterion is the element of tempo. This element becomes a barometer of whether or not the character moves from one event to another hence readers can understand the difference between conflicts, certain situations and even the end of the story in the novel. The tempo development has an impact on the quality of the reader's understanding. The 
tempo of the novel can be determined through the development of the story presented through the novel's characters. Therefore, the questionnaire focused on the relationship between character actions and story development. This can be seen in Table 17. as follows:

Table 17. Questionnaire Data for Tempo Assessment.

\begin{tabular}{lccccc}
\hline Scoring scale & 1 & 2 & 3 & 4 & Total \\
\hline Number of respondents (people) & 0 & 8 & 25 & 2 & 35 \\
Percentage (\%) & 0 & 22,9 & 71,4 & 5,7 & 100 \\
\hline
\end{tabular}

Based on Table 17, all informants provide an assessment of the Huo Zhe (活着) novel. The total number of informants who gave an assessment was 35 people. The informant did not give an assessment of a score 1 . The lowest score given to the tempo factor was 2, while the highest score was 4 . As many as 8 people with a percentage of $22.9 \%$ gave a score of 2 , which means that the development of the story was judged by the readers did not move too fast. A score of 3 was given by 25 informants with a percentage of $71.4 \%$, which means that they agreed that the character's action causes the story to progress quickly. Furthermore, the highest score was 4 consisting of 2 informants with a percentage of $5.7 \%$ which means that they strongly agreed if the character's actions affect the fast-development of the story. The results of the data that have been obtained were then reprocessed to obtain the average score. The following were the results of the data processing:

Table 18. Average Reader's Response Score for the Tempo Element

\begin{tabular}{lcccccc}
\hline & N & Minimum & Maximum & Mean & $\begin{array}{c}\text { Std. } \\
\text { Deviation }\end{array}$ \\
\hline N Valid general criteria & 35 & 2 & 4 & 2,83 & 0,51 \\
\hline
\end{tabular}

Table 18 showed the minimum score given by the informants was 2 and the maximum score was 4 . The average score was 2.83. Based on these results, it can be interpreted that the actions presented in the Huo Zhe (活着) novel did not have a fast tempo of the entire story development hence readers can understand the movement of events from one to another.

\subsection{Reader's Response Based on the Impact Factors on Yu Hua's Novel Huo Zhe (活着)}

This section discussed the responses given by the informants regarding the design criteria for the novel. The responses focus on plot, theme and structure. A plot is an event in a story that is interconnected and has a causal relationship (cause-effect). The plot is able to create tension and resolution in the story; hence this can increase the reader's interest in literary works. Therefore, a plot as one of the elements forming literary works is very important to be assessed. The plot is also considered as one of the design factors that determine the success of the story. This can be seen in the table as follows:

Table 19. Questionnaire Data for Plot Assessment.

\begin{tabular}{lccccc}
\hline Scoring scale & 1 & 2 & 3 & 4 & Total \\
\hline Number of respondents (people) & 0 & 0 & 26 & 9 & 35 \\
Percentage $(\%)$ & 0 & 0 & 74,3 & 25,7 & 100 \\
\hline
\end{tabular}

Based on Table 19, all informants provide an assessment of the Huo Zhe (活着) novel. The total number of informants who gave an assessment was 35 people. Informants did not provide an assessment of a score of 1 and 2 . The minimum score given by the informants was 3 and the highest was 4 . A total of 26 people gave a score of 3 with a percentage of $74.3 \%$, which means that the plot in the novel was well developed and clear. The remaining 9 people with a total percentage of $25.7 \%$ gave a score of 4 , which means that the informants considered the plot was developed very well and clearly. The results of the data analysis then reprocessed to obtain the average score. The following were the results of the data processing:

Table 20. Average Reader's Response Score for the Plot Elements

\begin{tabular}{lcccccc}
\hline & N & Minimum & Maximum & Mean & $\begin{array}{c}\text { Std. } \\
\text { Deviation }\end{array}$ \\
\hline N Valid general criteria & 35 & 3 & 4 & 3,26 & 0,44 \\
\hline
\end{tabular}

Table 20. showed the minimum score given by the informants was 3 and the maximum score was 4 . The average score was 3.26. Based on these scores, it can be interpreted that the Huo Zhe (活着) novel has a plot design that is coherent, developing, well organized and clear to readers.

Furthermore, the design criteria also consist of 'theme' elements. The theme is the main idea of a story told by the author. 
Themes as a result of the conclusions of various events are closely related to characterizations and settings hence they underlie the course of a story. Therefore, the questionnaire focused on the theme of the novel. This can be seen in the table as follows:

Table 21. Questionnaire Data for Theme Assessment.

\begin{tabular}{lccccc}
\hline Scoring scale & 1 & 2 & 3 & 4 & Total \\
\hline Number of respondents (people) & 0 & 0 & 18 & 17 & 35 \\
Percentage $(\%)$ & 0 & 0 & 51,4 & 48,6 & 100 \\
\hline
\end{tabular}

Based on Table 21, all informants provide an assessment of the Huo Zhe (活着) novel. The total number of informants who gave an assessment was 35 people. Informants did not provide an assessment of a score of 1 and 2 . The lowest score given by the informant was 3 and the highest score given was 4 . The informants who gave 3 as score were 18 people with a percentage of $51.4 \%$, which means that the informants agreed that the novel raised a big theme related to people's lives. Meanwhile, the informants who gave a score of 4 were 17 people with a percentage of $48.6 \%$, which means that the informants strongly agreed with the novel taking the idea of a crucial theme. The results of the data analysis then reprocessed to obtain the average score. The following were the results of the data processing:

Table 22. Average Reader's Response Score for Theme Elements

\begin{tabular}{lcccccc}
\hline & N & Minimum & Maximum & Mean & $\begin{array}{c}\text { Std. } \\
\text { Deviation }\end{array}$ \\
\hline N Valid general criteria & 35 & 3 & 4 & 3,49 & 0,51 \\
\hline
\end{tabular}

Table 22. showed the minimum score given by the informants was 3 and the maximum score was 4 . The average score was 3.49. Based on these scores, it can be interpreted that the theme described by the novel regarding the struggle for life is well responded to by readers.

Furthermore, the final part of the design criteria is the structural element. A structure is a set of patterns that are arranged in an orderly manner and consist of small parts that form a whole. A literary work is formed by an arrangement of small patterns that are interrelated and meaningful. These patterns can be in the form of words, sentences, prologues, monologues, dialogues, flow, characterizations, settings, themes, messages and so on. This assessment was chosen to evaluate the integrity of the novel as a literary work. In that sense, structural assessment is used to measure the unity and cohesiveness of the elements forming a literary work. In this assessment, the scores given by the informants regarding the structure of the Huo Zhe (活着) novel were as follows:

Table 23. Questionnaire Data for Theme Assessment.

\begin{tabular}{lccccc}
\hline Scoring scale & 1 & 2 & 3 & 4 & Total \\
\hline Number of respondents (people) & 0 & 1 & 24 & 10 & 35 \\
Percentage $(\%)$ & 0 & 2,9 & 68,6 & 28,6 & 100 \\
\hline
\end{tabular}

Based on Table 23, all informants provide an assessment of the Huo Zhe (活着) novel. The total number of informants who gave an assessment was 35 people. The informant did not give a score of 1 . From the data above, it can be seen that the informant gave 2 as the lowest score and the highest score was 4 . The informant who gave a score of 2 was only 1 person with a percentage of $2.9 \%$, which means that the novel structure was considered not coherently integrated. Informants who gave a score of 3 were 24 people with a percentage of $68.6 \%$ considered all novel structures to be coherently integrated and 10 people who gave a score of 4 with a percentage of $28.6 \%$ considered strongly agree if the novel structure was coherently integrated. The results of the data analysis were then reprocessed to obtain the average score. The following were the results of the data processing:

Table 24. Average Score of Readers' Responses for Structural Elements

\begin{tabular}{lccccc}
\hline & N & Minimum & Maximum & Mean & $\begin{array}{c}\text { Std. } \\
\text { Deviation }\end{array}$ \\
\hline N Valid general criteria & 35 & 2 & 4 & 3,26 & 0,50 \\
\hline
\end{tabular}

Table 24. showed the minimum score given by the informants was 2 and the maximum score was 4 . The average score was 3.26. Based on these scores, it can be interpreted that the reader responds to all elements of the Huo Zhe (活着) novel as having a good structure and coherently integrated. 


\section{Conclusion}

The era of globalization has made people increasingly aware of the importance of learning foreign languages, including Mandarin. It is undeniable that Mandarin has now become an important necessity for anyone who wants to survive the intensity of global competition. This success in mastering Mandarin cannot be separated from the role of literature. In this case, readers have an important position in the world of literature, especially Chinese literature. Chinese literature as one of the oldest literature in the world has a long journey in describing Chinese civilization. Literary works that were born in the area of Chinese literature can then be read from various audiences, especially readers from students majoring in Chinese Language, Faculty of Cultural Studies, University of Sumatera Utara.

Based on the analysis results presented, it can be concluded that the informants in this study responded positively to the Huo Zhe (活着) novel. The Huo Zhe (活着) novel fulfills the evaluation criteria of novelty, impact and design as proposed by Segers in his theory. In the criteria of novelty or renewal, this novel was responded to have good categories, related to elements of language presentation, original and interesting ideas or issues, and interest in conducting further analysis. However, on the element of satisfaction, this novel did not give the reader a happy impression because the novel's story mostly displays the sadness and sorrow of the Fugui character in living his life. Furthermore, on the criteria of impact, this novel was responded to have good categories, related to the emotional element of the reader, the logic of the story, the characterization that can be visualized with the reality of society, the involvement that brings the reader into the story conveyed by the novel and the slower tempo of the storytelling. Also, the design criteria for this novel were responded to have good categories, related to the plot elements that are easy to understand, interesting themes and the structure displayed that was coherent with others. Thus, from the three evaluations, it can be concluded that the reading informants from the 6th and 8th semester students of the Chinese Language major accept the Huo Zhe (活着) novel as good and positive reading material.

\section{References}

[1] Endaswara, Suwardi (2008) "Metodologi Penelitian Sastra", Yogyakarta, Media Pressindo.

[2] Hua, Yu (2004) "Huo Zhe", Beijing, Zhongguo Chang Pian Zong Gong Si.

[3] Junus, Umar (1985) "Resepsi Sastra, Sebuah Pengantar", Jakarta, Gramedia.

[4] Kurniawan, Heru (2012) "Teori, Metode, dan Aplikasi Sosiologi”, Yogyakarta, Graha Ilmu.

[5] Segers, Rien T (2000) "Evaluasi Teks Sastra", Yogyakarta, Adicita Karya Nusa.

[6] Sehandi, Yohannes (2014) "Mengenal 25 Teori Sastra", Yogyakarta, Ombak.

[7] Sukmadinata, N.S (2011) "Metode Penelitian Pendidikan", Bandung, Remaja Rosadakarya.

[8] Prastowo, Andi (2011) "Metode Penelitian Kualitatif dalam Perspektif Rancangan Penelitian", Yogyakarta, Ar-Ruzz Media. 